\title{
Numerical Study on Energy Dissipation of Steel Moment Resisting Frames under Effect of Earthquake Vibrations
}

\author{
Mohsen Gerami $^{1}$ and Davood Abdollahzadeh ${ }^{2}$ \\ ${ }^{1}$ Earthquake Engineering Group, Faculty of Civil Engineering, Semnan University, \\ Semnan 35131-19111, Iran \\ ${ }^{2}$ Faculty of Engineering, Islamic Azad University of Pardis, Tehran 16555-135, Iran \\ Correspondence should be addressed to Davood Abdollahzadeh; davood.abdollahzadeh@gmail.com
}

Received 2 September 2013; Accepted 25 November 2013; Published 13 March 2014

Academic Editor: Marc Asselineau

Copyright ( $) 2014$ M. Gerami and D. Abdollahzadeh. This is an open access article distributed under the Creative Commons Attribution License, which permits unrestricted use, distribution, and reproduction in any medium, provided the original work is properly cited.

\begin{abstract}
In the regions near to active faults, if the fault rupture propagation is towards the site and the shear wave propagation velocity is near the velocity of fault rupture propagation, the forward directivity effect causes pulse-like long-period large-amplitude vibrations perpendicular to the fault plane which causes a large amount of energy to be imposed to structures in a short time. According to previous investigations, the amounts of input and dissipated energies in the structure represent the general performance of the structure and show the level of damage and flexibility of the structure against earthquake. Therefore, in this study, the distribution of damage in the structure height and its amount at the height of steel moment frames under the pulse-like vibrations in the near fault region has been investigated. The results of this study show that the increase rate of earthquake input energy with respect to increase in the number of stories of the structure in the near field of fault is triple that in the far field of fault which then leads to a 2-2.5 times increase in the earthquake input energy in the high rise moment frames in the near field of fault with respect to that in the far field of fault.
\end{abstract}

\section{Introduction}

In recent decades, the energy concepts have found their way in the earthquake engineering, in such a way that energy concepts now have applications in optimization design [1] and vulnerability evaluation of the structures under earthquake and therefore researchers have proposed some methods for designing the structures [2]. Housner was the first one who brought about the energy method for the seismic design $[3,4]$ and in 1999, designing of moment frames according to energy was proposed by Leelataviwat et al. [5, 6]. The common seismic design methods which are based on strength demand and deformation control estimate the earthquake intensity by means of Peak Ground Acceleration (PGA) or Effective Peak Acceleration (EPA) $\left(\mathrm{EPA}=\bar{S}_{a} / 2.5, \bar{S}_{a}\right.$ is average spectral acceleration of velocity-sensitive region of response spectrum (ATC 3-06, 1978)) and then estimate the earthquake forces imposed on the structure by response spectrum, main period, and the effective weight of the structure. These methods do not consider the duration parameter of earthquake and its effect on the structure hysteresis behavior, while in the seismic design methods which are based on energy all the structure and earthquake parameters such as frequency, earthquake duration, and structure specifications such as ductility, damping, the structure natural oscillation period, and hysteresis behavior are considered [5]. In the near field of the fault, due to the effects of forward directivity, the earthquake energy is imposed by means of a small number of oscillation cycles in the direction perpendicular to the fault line which then leads to more demands such as base shear and relative displacements in the structure [7-16]. In order to investigate the seismic behavior of the structures in the near field of fault, many investigations have been carried out so far which have mostly been based on displacement 


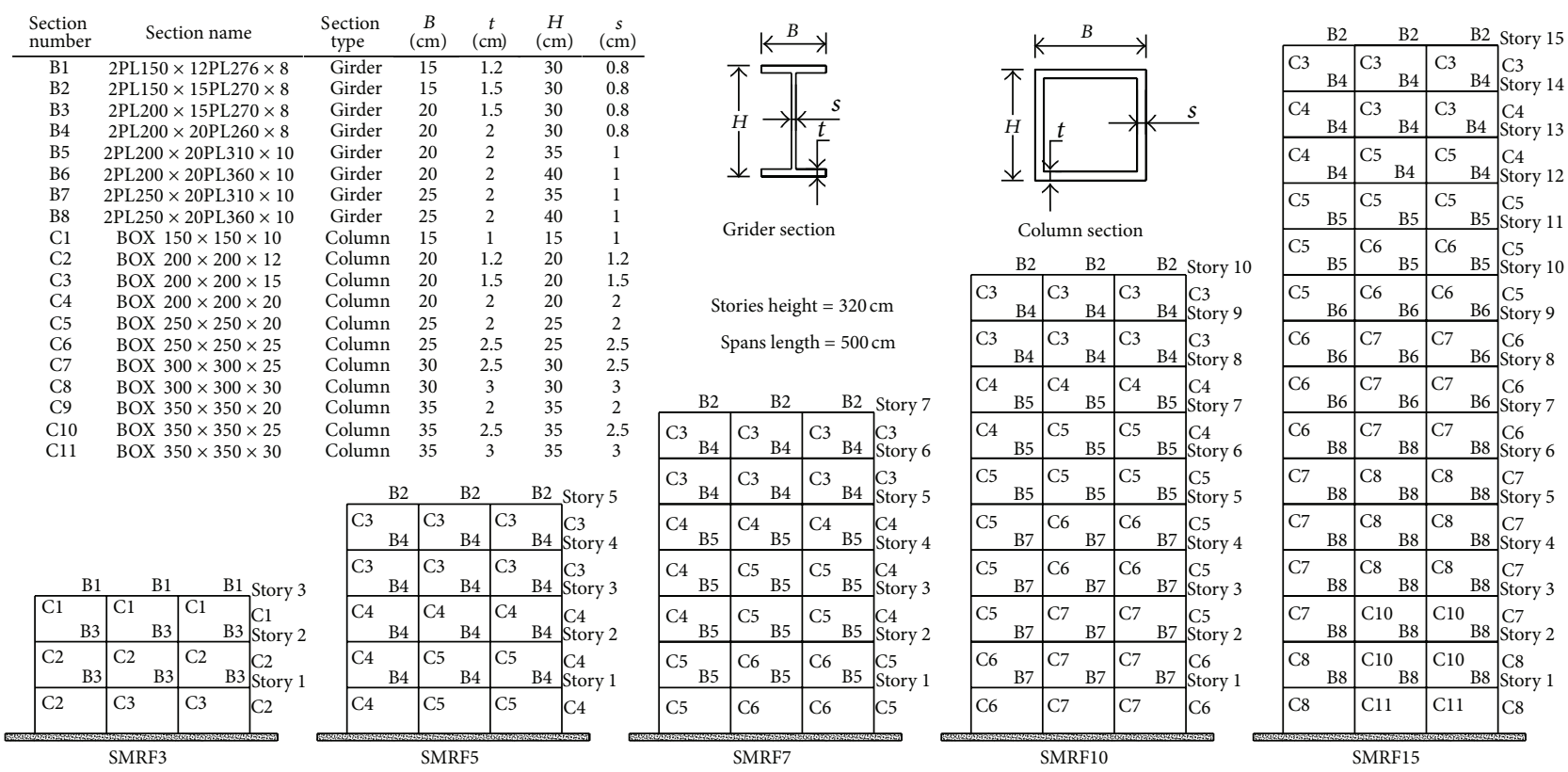

FIgURE 1: The structural models used in this study.

methods. Most of the investigations done on the near field of fault have focused on the deformations of the structure and structural elements and finally have determined the seismic performance of the structure [9-11]. According to the statements given above, in this study in order to better understand the seismic behavior of steel moment frames in the near field of the fault and finding out the way the vulnerability is distributed through the height, the distribution pattern of earthquake energy dissipation at the height of steel moment frames under the effect of forward directivity in the near field of the fault has been studied. In order to do this, five 2D steel moment frames with heights of 3, 5, 7, 10, and 15 stories have been designed according to Iran seismic design code. After that, the input energy of the records and the dissipated energy at the stories of the structural models have been determined by means of nonlinear dynamic analysis under 20 earthquake accelerograms in the near and far fields of the fault and then the results have been investigated at the whole height of the models.

\section{Structural Models Design}

The structural samples are five 2D steel moment frames with 3 spans with story heights of 3.2 meters and span lengths of 5 meters. The moment frames have $3,5,7,10$, and 15 stories. The gravity loading of the models are based on Iranian loading code. For all models, the dead and live loads of the stories except roof are $2500 \mathrm{~kg} / \mathrm{m}$ and $1000 \mathrm{~kg} / \mathrm{m}$, respectively. The dead load of roof is $1750 \mathrm{~kg} / \mathrm{m}$ for 3-story and 5-story models, $2083 \mathrm{~kg} / \mathrm{m}$ for the 7 -story and 10-story models, and $2250 \mathrm{~kg} / \mathrm{m}$ for the 15-story model. The live load of roof is the same for all models, as it is $750 \mathrm{~kg} / \mathrm{m}$. The seismic loading is according to Iran seismic design code 3rd edition (Standard 2800 3rd edition, 2005). All the models were designed for the regions with high seismic hazard in the site condition of stiff soil (Class D based on FEMA356 soil classification). Iran seismic design code suggests the Peak Ground Acceleration to be $0.35 \mathrm{~g}$ for the regions with high seismic hazard and for $10 \%$ probability of earthquake occurrence in a 50 year useful life of the structure. This code has not provided a different PGA for the near field of the fault. In other words, the PGA given by Iran seismic design 3rd edition is the same for the equal level of hazard in the near and far fields of the fault. Other parameters of seismic design which consist of structure main period, importance factor related to residential buildings, reduction factor of 10 , limitation in the maximum of relative displacement, and the effects of $P-\Delta$ in analysis and design of structures have been considered. According to Iran steel structures design code, steel structural elements are made of ST37 with the specifications of yield strength of $f_{y}=2400 \mathrm{~kg} / \mathrm{cm}^{2}$, ultimate strength of $3600 \mathrm{~kg} / \mathrm{cm}^{2}$, elastic modulus of $2.1 \times 10^{6} \mathrm{~kg} / \mathrm{cm}^{2}$ and Poisson ratio of 0.3 . The structural elements have been chosen from the type of seismic compact sections and the beams have been designed by assuming enough lateral supports. Figure 1 shows the details of structural samples.

\section{The Accelerograms Used for Nonlinear Dynamic Analysis of the Structures}

In the near field of the fault, when the earthquake shear wave propagation velocity is close to the rupture propagation velocity of the fault plane and the direction of the fault rupture propagation is towards the site, then strong vibrations of the ground will be pulse-like with long period and low numbers of oscillations, short effective duration and high amplitude which are effective in the direction perpendicular to the fault plane [7-17]. The pulse-like vibrations are clearly seen in 
TABLE 1: The records used for this study.

\begin{tabular}{|c|c|c|c|c|c|c|c|c|c|}
\hline $\begin{array}{l}\text { Earthquake name } \\
\text { Date (yy-mm-dd) }\end{array}$ & Station & Com.-Azi. ${ }^{a}$ & $R^{\mathrm{b}}(\mathrm{Km})$ & $\mathrm{PGA}^{\mathrm{c}}(\mathrm{g})$ & $\mathrm{PGV} \mathrm{PGA}^{\mathrm{d}}(\mathrm{s})$ & $\mathrm{CAV}^{\mathrm{e}}(\mathrm{m} / \mathrm{s})$ & $\operatorname{Tp}^{f}(s)$ & $\operatorname{Tm}^{\mathrm{g}}(\mathrm{s})$ & P. $\operatorname{Tp}^{\mathrm{h}}(\mathrm{s})$ \\
\hline Chi-Chi, Taiwan, 99-09-20 & CHY065 & $\mathrm{N}-0^{\circ}$ & 83.43 & 0.1 & 0.14 & 9.88 & 0.56 & 0.79 & $-^{*}$ \\
\hline Chi-Chi, Taiwan, 99-09-20 & TAP095 & $\mathrm{E}-90^{\circ}$ & 109.01 & 0.15 & 0.18 & 56.56 & 0.98 & 0.84 & $-^{*}$ \\
\hline Loma Prieta, 89-10-18 & CDMG58224 & $290^{\circ}$ & 72.2 & 0.24 & 0.15 & 27.69 & 0.32 & 0.86 & $-^{*}$ \\
\hline Loma Prieta, 89-10-18 & CDMG58472 & $270^{\circ}$ & 74.26 & 0.26 & 0.16 & 28.35 & 0.64 & 0.85 & $-^{*}$ \\
\hline Kobe, Japan, 95-01-16 & HIK & $0^{\circ}$ & 95.72 & 0.14 & 0.11 & 45.02 & 0.6 & 0.76 & - $^{*}$ \\
\hline Loma Prieta, $89-10-18$ & CDMG58223 & $0^{\circ}$ & 58.65 & 0.23 & 0.11 & 33.26 & 0.3 & 0.53 & $-^{*}$ \\
\hline Manjil, Iran, 90-06-20 & Qazvin & $336^{\circ}$ & 49.97 & 0.13 & 0.09 & 59.48 & 0.16 & 0.46 & $-^{*}$ \\
\hline Northridge, 94-01-17 & CDMG13122 & $0^{\circ}$ & 82.32 & 0.10 & 0.07 & 31.22 & 0.38 & 0.44 & $-^{*}$ \\
\hline Tabas, Iran, 78-09-16 & Ferdows & $\mathrm{T} 1$ & 91.14 & 0.10 & 0.08 & 48.38 & 0.24 & 0.29 & $-^{*}$ \\
\hline Kocaeli, Turkey, 99-08-17 & Bursa Tofas & $90^{\circ}$ & 60.43 & 0.10 & 0.21 & 100.90 & 0.68 & 0.93 & $-^{*}$ \\
\hline Denali, Alaska, 02-11-03 & Pump st. 10 & $47^{\circ}$ & 2.74 & 0.32 & 0.43 & 47.83 & 0.94 & 1.52 & 12.38 \\
\hline Bam, Iran, 03-12-26 & Bam & $\mathrm{T} 3-8^{\circ}$ & $R<15$ & 0.59 & 0.43 & 118.26 & 0.78 & 0.91 & 7.24 \\
\hline Chi-Chi, Taiwan, 99-09-20 & CHY101 & $\mathrm{N}-0^{\circ}$ & 9.96 & 0.44 & 0.27 & 48.15 & 0.9 & 0.98 & 5.98 \\
\hline Chi-Chi, Taiwan, 99-09-20 & TCU068 & $\mathrm{E}-90^{\circ}$ & 0.32 & 0.56 & 0.32 & 30.52 & 0.42 & 1.51 & 12.19 \\
\hline Imperial Valley, 79-10-15 & CDMG 5158 & $230^{\circ}$ & 1.35 & 0.43 & 0.26 & 23.33 & 0.24 & 1.31 & 3.86 \\
\hline Northridge, $94-01-17$ & DWP 75 & $288^{\circ}$ & 5.19 & 0.49 & 0.15 & 25.50 & 0.22 & 0.72 & 3.48 \\
\hline Silakhor, Iran, 06-03-31 & Chalan Cho. & $\mathrm{L}-99^{\circ}$ & $R<15$ & 0.45 & 0.33 & 93.81 & 1.52 & 1.82 & 8.62 \\
\hline Kocaeli, Turkey, 99-08-17 & Yarimca & $60^{\circ}$ & 4.83 & 0.26 & 0.25 & 39.12 & 0.52 & 1.29 & 4.9 \\
\hline Zanjiran, Iran, 94-06-20 & Meymand & $\mathrm{L}-0^{\circ}$ & $R<15$ & 0.42 & 0.28 & 123.41 & 1.36 & 1.73 & 2.34 \\
\hline Kobe, Japan, 95-01-16 & Takatori & $0^{\circ}$ & 1.47 & 0.61 & 0.21 & 42.52 & 1.22 & 1.10 & 1.68 \\
\hline
\end{tabular}

${ }^{\mathrm{a}}$ Component-Azimuth. ${ }^{\mathrm{b}}$ Closest distance from the recording site to the ruptured area. ${ }^{\mathrm{c}}$ Peak Ground Acceleration. ${ }^{\mathrm{d}}$ Peak Ground Velocity to Peak Ground Acceleration ratio. ${ }^{\mathrm{e}}$ Cumulative Absolute Velocity. ${ }^{\mathrm{f}}$ Predominant Period. ${ }^{\mathrm{g}}$ Mean Period. ${ }^{\mathrm{h}}$ Pseudo pulse period.

${ }^{*} \mathrm{P}$. Tp is calculated for near fault pulse-like motions and calculation of it for non-pulse-like motions in far field of fault is not valid [14].

velocity record perpendicular to the fault plane most of the time [7-17]. The other effect of forward directivity is filing step or ground permanent displacement which occurs in the direction parallel to the fault slip [7-9]. The previous studies have shown that, compared to other forward directivity effects, pulse-like vibrations in the near field of the fault have more damaging effects on the engineering structures in the direction perpendicular to the fault line [7-17]. The earthquake magnitude, site conditions, velocity pulse period, and the peak point of velocity time history have important roles in increasing the effects of forward directivity in the near field of the fault $[7,9,11,13,14]$. The effects of forward directivity decrease by increasing the distance with the fault. After a particular distance, these effects completely disappear; in this case, the regions are under the effect of neutral directivity [15]. All of the used accelerograms used in this study are chosen from the well-known earthquakes with magnitudes higher than 6.5 which are recorded in sites with stiff soils (Class D based on FEMA356 soil classification). According to references $[7,15]$, in order to investigate the structural models under the effect of forward directivity, the records of the near field of the fault have been chosen in such a way that first, the records have short effective duration, high amplitude, and pulse-like effects with long period (higher than $0.7 \mathrm{~s}$ ) in the velocity record; Second, the maximum distance of the place where the records are recorded is not higher than 15 kilometers from the fault; Third, the records of the near field of fault have been chosen in such a way that they have higher ratio of PGV/PGA with respect to that of the far field of fault; and fourth, the amount of their response spectrum in the range of long period $(T>1 \mathrm{~s})$ is higher with respect of that in the far field of the fault. According to reference [15], in order to prevent the effect of the number of oscillation in the earthquakes recorded very far from the fault with negligible PGA, the far fault ground motion records in the regions having neutral directivity and PGA $>0.1 \mathrm{~g}$ were chosen. Table 1 shows the records used for the nonlinear dynamic analysis.

\section{Details of Modeling and Nonlinear Dynamic Analysis of Structural Models}

For analyzing the structural samples, Perform 3D v4 package has been used according to the following assumptions.

(a) According to Iran seismic design code, the structural samples have been designed in such a way that their elements have high ductility capacities in order to prevent the brittle fracture of the structure during the earthquake. Therefore, according to FEMA356, the plastic hinges have been considered based on the force-displacement relationship of the ductile structural elements in Figure 2. In order to determine the force-displacement relationship parameters $(a, b$, and $c)$ in Figure 2, Table 3 has been used. 
It is noteworthy to say that the beams and columns connections are assumed to be rigid.

(b) The time steps for the records have been set to $0.005 \mathrm{~s}$ and in order to control the analysis stopping, maximum 500 substeps have been considered for each time step.

(c) In the nonlinear dynamic analysis, the effects of large deformations have been considered.

(d) According to the recommendations of Iran seismic design code, $5 \%$ critical damping has been considered for dynamic analysis of the models [18].

(e) Iran seismic design code has proposed the PGA of $0.35 \mathrm{~g}$ for designing the structures in the regions with $10 \%$ of earthquake occurrence for the 50 useful lifetime of the structure [18]. This code has not suggested other amounts of PGA in the near field of fault for the above hazard level. Since in this study the aim is to investigate the behavior of structural models by assuming the same hazard levels at near and far fields of the fault, therefore the accelerograms of Table 1 have been scaled to the peak acceleration of $0.35 \mathrm{~g}$ according to Iran seismic design code (2005). Anyway, it must be stated that for design purposes, other methods must be used for scaling the actual records of earthquake.

(f) According to FEMA356 codes, if seven or higher number of earthquake records are implemented for analyzing the time history, the average results of maximum earthquakes response can be used. Therefore, in this study, the average of maximum results of models analyses has been used in the near and far fields of fault in order to compare the parameters of structure response.

\section{Study of Energy Equilibrium Equation in the Structure}

During the earthquake, depending on the site conditions, structure specifications, and the contents of ground vibration frequency, the structures receive different amounts of earthquake energy. The energy transferred to the structure by the earthquake causes oscillating responses in the structure which depending on the severity of the vibration creates elastic and inelastic deformations in the structural elements. Therefore during the earthquake, the total energy caused by oscillating response consists of kinetic energy $\left(E_{k}\right)$, elastic strain $\left(E_{\mathrm{es}}\right)$, and the dissipated energies in the structure consist of damping energy $\left(E_{\zeta}\right)$ and hysteresis energy $\left(E_{h}\right)$ (1). Using (2), the energy entering the structure by the earthquake $\left(E_{i}\right)$ can be determined for a multi-degree-offreedom system:

$$
\begin{gathered}
E_{i}=E_{k}+E_{\zeta}+E_{\mathrm{es}}+E_{h}, \\
E_{i}=-\int_{0}^{t} \dot{\mathbf{u}}^{T} \mathbf{M r} \ddot{\mathbf{u}}_{g} d \mathbf{t} .
\end{gathered}
$$

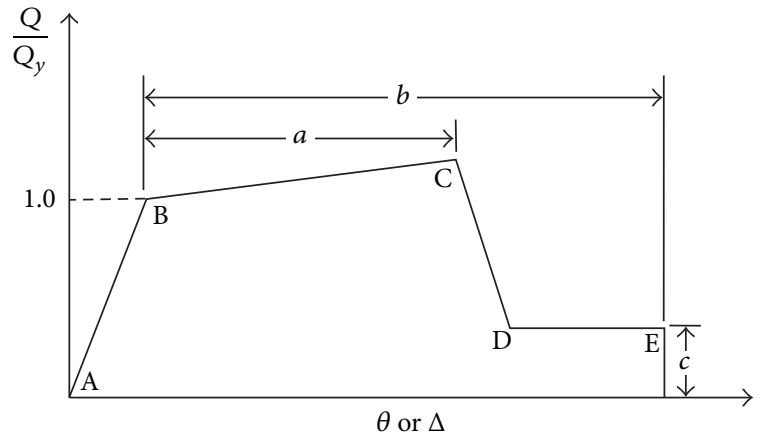

FIGURE 2: The force-displacement relationship for the ductile structural elements [19].

In (2), $\mathbf{u}$ is the (relative) velocity of the degrees of freedom, $\mathbf{r}$ is the influence vector (influence coefficient matrix), $\ddot{\mathbf{u}}_{g}$ is the ground acceleration, and $\mathbf{t}$ is the earthquake accelerogram duration [19].

According to (2), the input energies of the records of the near and far fields of the fault have been investigated in Figures 3 and 4 . Investigating the input energies of each of the earthquakes for the structural models in Figure 3 shows that the increase rate of earthquake energy with respect to increase in the number of stories of the structure for the near field of the fault is triple of that for the far field of the fault. As it can be seen in Figure 4, the average ratio of input energy of near field of fault over the far field of the fault is 1.27 for the 3-story model, while it has reached 2.5 for the 15-story model. This shows that pulse-like vibrations of the ground in the near field of fault have more destructive effects on the high rise (long period) structures in comparison with low rise structures.

Investigation of accumulative input energies in the near and far fields of the fault over time shows that in the near field of fault, the time at which $90 \%$ of earthquake energy has been transferred to the structure is at least $50 \%$ lower than that time for the records of the far field of fault. It is in such a way that it can be seen that in the near field of the fault, most of the earthquake energy is accumulated in the period when the forward directivity pulse is imposed. On the other hand, in the far field of the fault, the earthquake energy is distributed almost equally in the time. Figure 5 shows this for the 3 -story model.

Figure 6 shows the time history of the inelastic, damping, strain elastic, and kinetic energies for the 3-story model under the time history of ground displacement of Kobe, Japan earthquake (1995) in the near and far fields of the fault. According to the inelastic accumulative energy diagram shown in Figure 6, the rise time of inelastic accumulative energy in the near field of the fault has reached its maximum value in a shorter time (more than $50 \%$ shorter) than that for the far field of the fault. As clearly seen, the most of inelastic energy of the near field of fault is concentrated in the period of pulse-like vibration, while for the far field region the inelastic energy is distributed in a longer time. Investigating the accumulative diagram of the damping energy in Figure 6 shows that during the pulse-like vibration of the ground, 


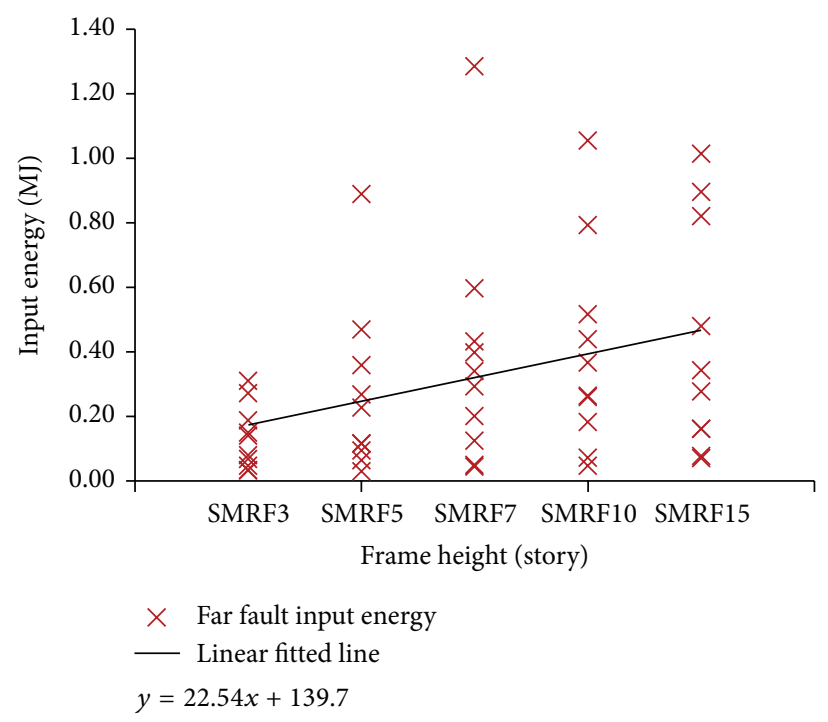

(a) Far field of fault

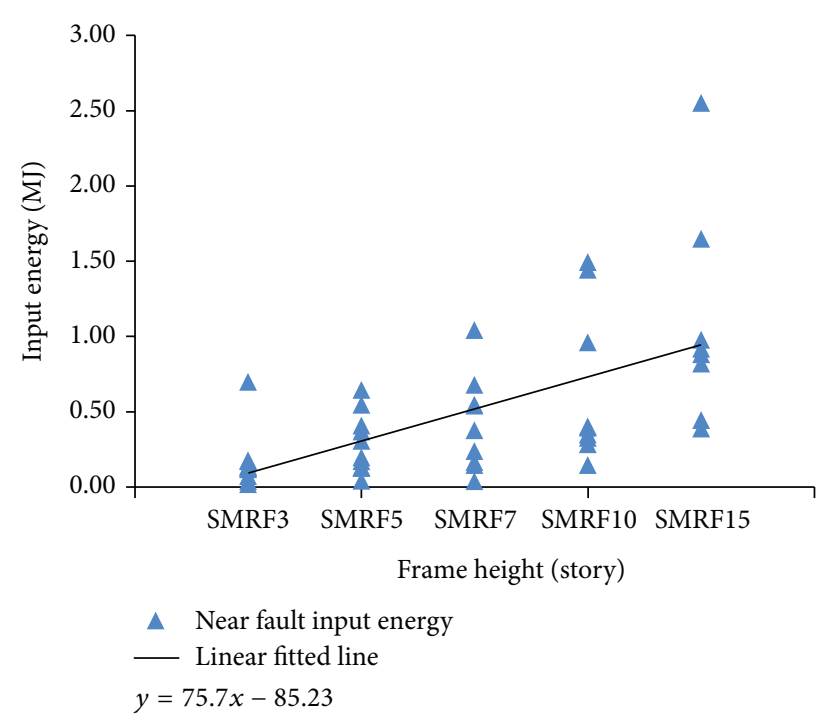

(b) Near field of fault

Figure 3: Increase in the input energy of the earthquake with respect to increase in the number of stories.

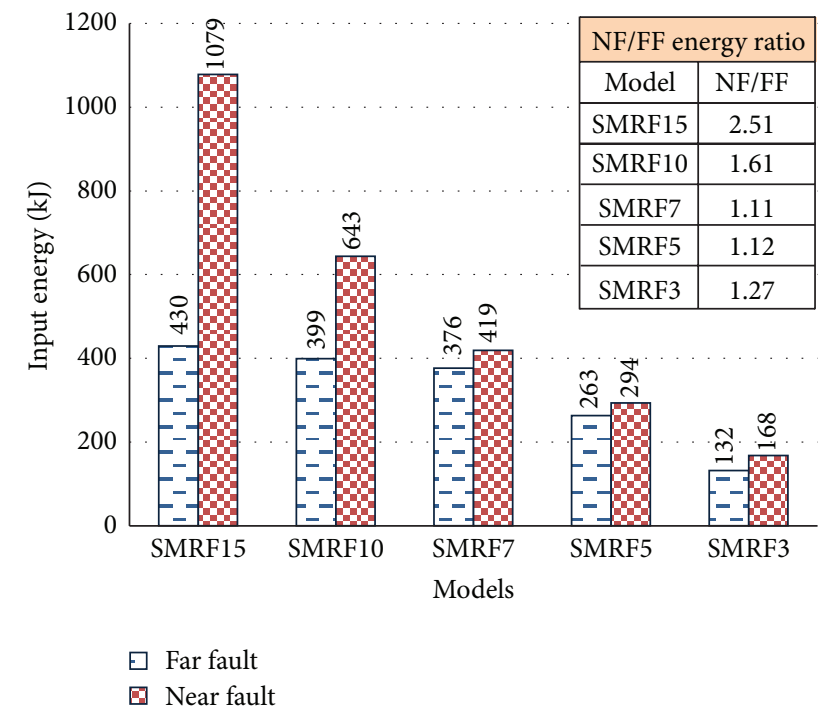

FIGURE 4: The average of input energies in the earthquakes in the near and far fields of fault.

the damping energy accumulative diagram in the near field of fault has higher slope than that in the far field of the fault (about 1.35 times for the 3-story model). This shows that in the instance of pulse vibration of the near fault field, most of the structure energy dissipation capacity is used by damping.

The results of relative displacement time history of 3story model in Figure 7 show that $60-90 \%$ of the earthquake energy is imposed on the structure after the directivity pulse which leads to the obvious inelastic deformation in the structure. Then, the structure oscillates around that deformation and at the end of the earthquake this deformation remains.

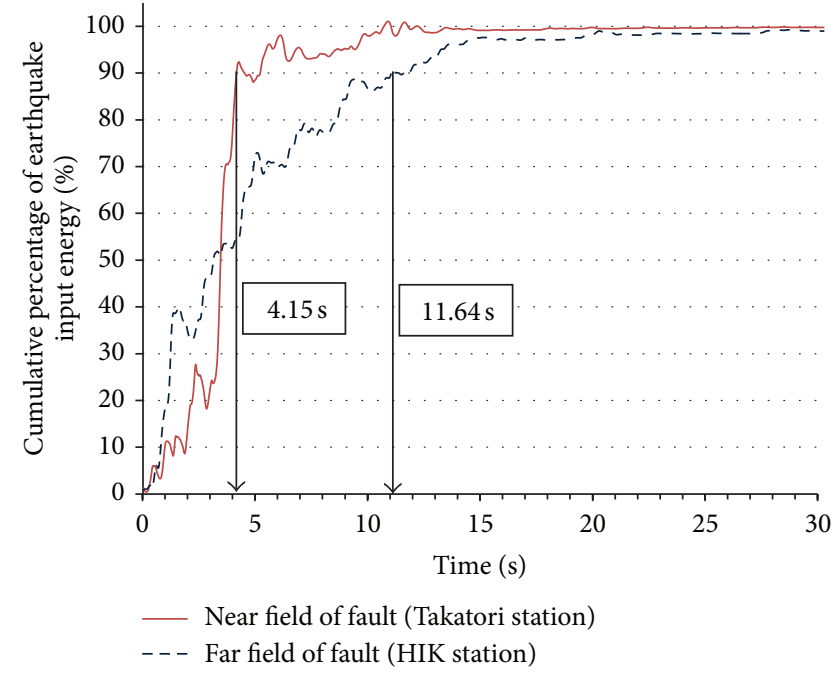

FIgURE 5: The percentage of accumulative energy in the Kobe, Japan, earthquake for the 3-story model in the near and far fields of fault.

Anyway, in the far field of the fault, the structure goes under several consecutive inelastic deformations in many directions which lead to permanent displacement at the end of the earthquake with lower (about 30\%) amplitude with respect to that in the near field of fault.

After the earthquake, if the structure is not destroyed, the free vibration of the structure dissipated the remaining strain and kinetic energies of the earthquake by means of damping. Therefore, after the free vibration of the structure, the sum of dissipated energy by damping and hysteresis is equal to the earthquake input energy. Equations (3), (4), and (5) give the kinetic energy $\left(E_{k}\right)$, damping energy $\left(E_{\zeta}\right)$, and sum of elastic 

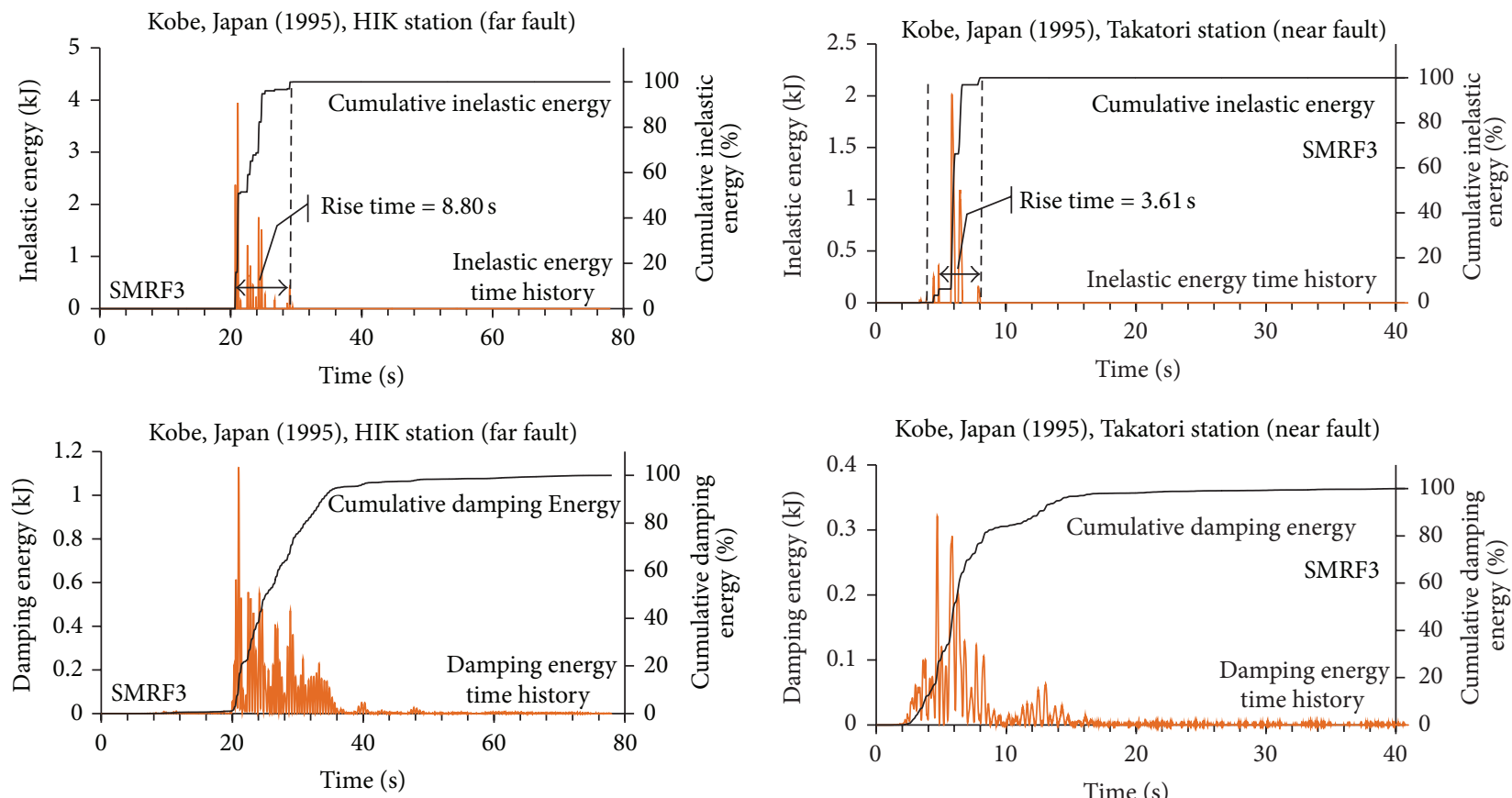

Kobe, Japan (1995), Takatori station (near fault)
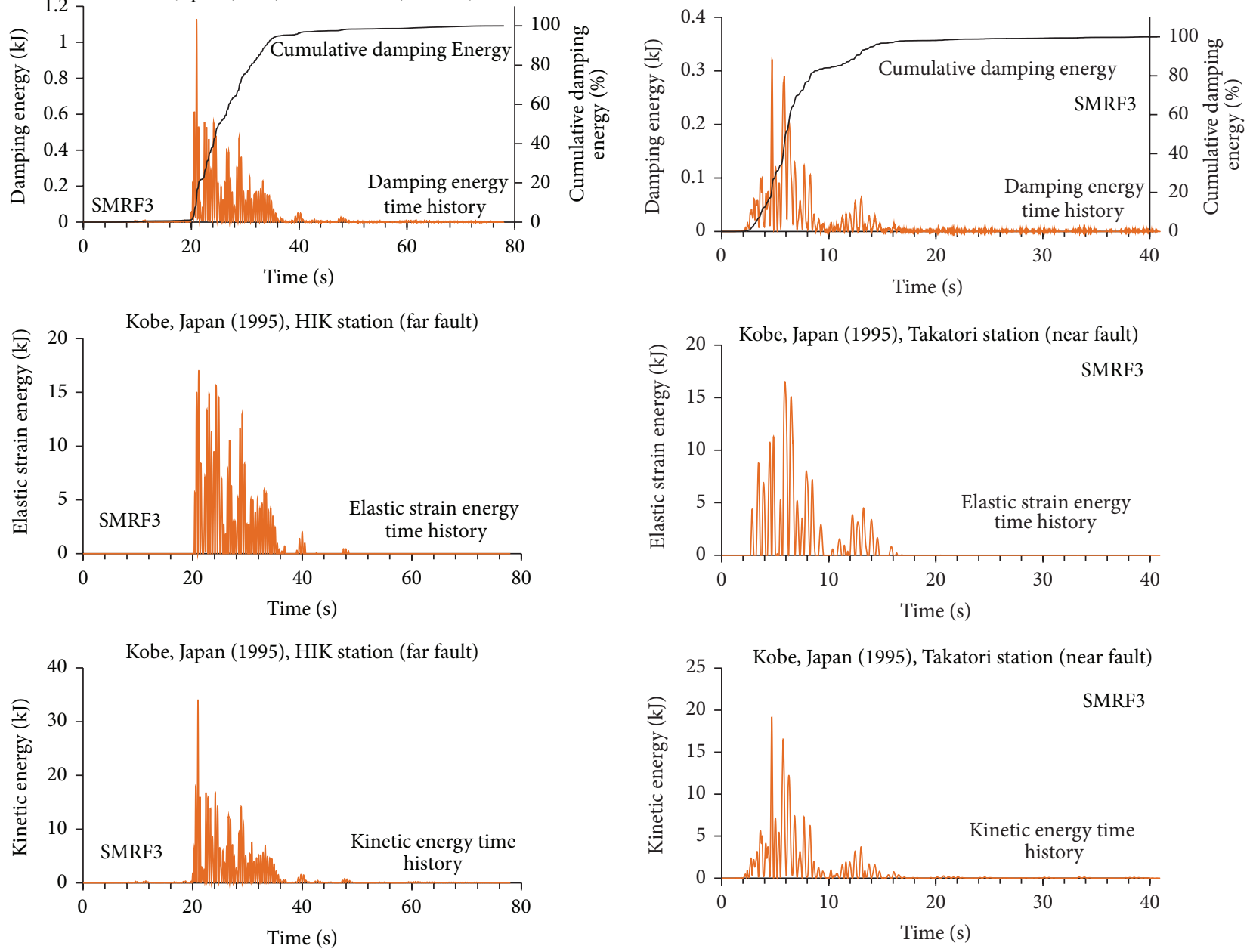

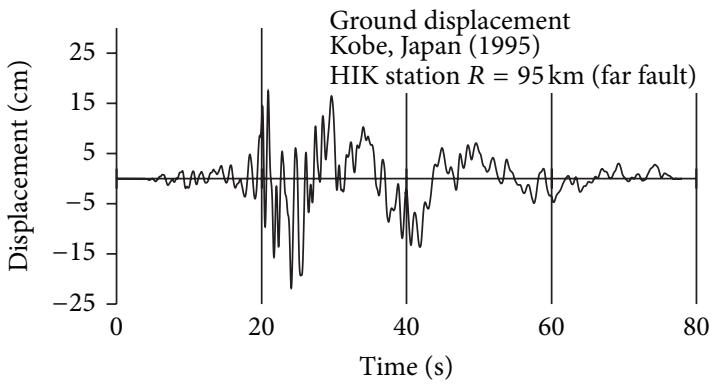

(a) Far field of fault

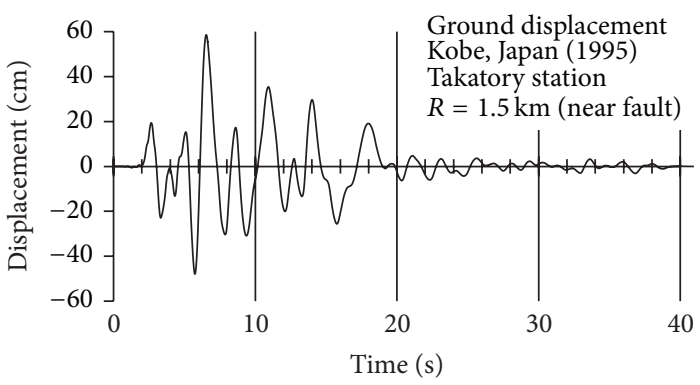

(b) Near field of fault

FIGURE 6: Time history of inelastic, damping, elastic strain, and kinematic energy of the 3-story model for Kobe earthquake, Japan (1995), in (a) far field of fault and (b) near field of fault. 
TABLE 2: Comparison of the average dissipated energy by damping and hysteresis behavior for the structural models in near and far field of fault.

\begin{tabular}{|c|c|c|c|c|c|c|}
\hline \multirow{3}{*}{$\begin{array}{l}\text { Structural } \\
\text { model }\end{array}$} & \multicolumn{3}{|c|}{ Far field of fault } & \multicolumn{3}{|c|}{ Near field of fault } \\
\hline & \multirow{2}{*}{$\begin{array}{l}\text { Earthquake } \\
\text { input energy } \\
(\mathrm{KJ})\end{array}$} & \multicolumn{2}{|c|}{ Dissipated energy } & \multirow{2}{*}{$\begin{array}{l}\text { Earthquake } \\
\text { input energy } \\
(\mathrm{KJ})\end{array}$} & \multicolumn{2}{|c|}{ Dissipated energy } \\
\hline & & $\begin{array}{l}\text { Damping } \\
(\mathrm{KJ})-(\%)\end{array}$ & $\begin{array}{l}\text { Hysteresis } \\
(\mathrm{KJ})-(\%)\end{array}$ & & $\begin{array}{l}\text { Damping } \\
(\mathrm{KJ})-(\%)\end{array}$ & $\begin{array}{l}\text { Hysteresis } \\
(\mathrm{KJ})-(\%)\end{array}$ \\
\hline SMRF15 & 430 & $395.93-95.5 \%$ & $33.79-4.5 \%$ & 1079 & $615.53-60.68 \%$ & $462.98-39.32 \%$ \\
\hline SMRF10 & 399 & $315-87.35 \%$ & $84.42-12.65 \%$ & 643 & $353.27-61.1 \%$ & $296.47-38.9 \%$ \\
\hline SMRF7 & 376 & $289.97-84.61 \%$ & $86.41-15.39 \%$ & 419 & $243.46-69.61 \%$ & $171.41-30.39 \%$ \\
\hline SMRF5 & 263 & $187.49-81.67 \%$ & $75.39-18.33 \%$ & 294 & $175.2-65.84 \%$ & $118.41-34.16 \%$ \\
\hline SMRF3 & 132 & $86.84-79.87 \%$ & $44.84-26.13 \%$ & 168 & $89.71-59.71 \%$ & $78.02-40.29 \%$ \\
\hline
\end{tabular}

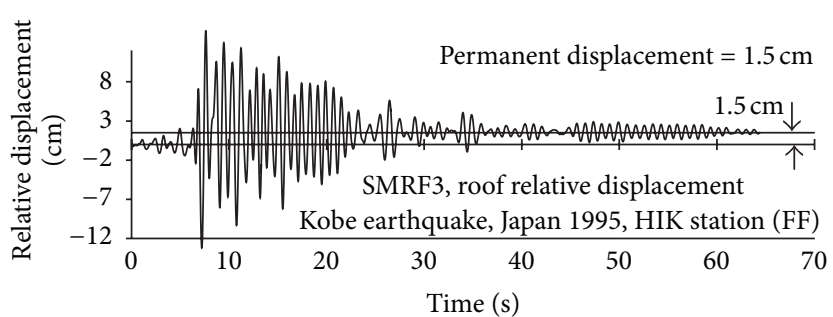

(a) Far field of fault

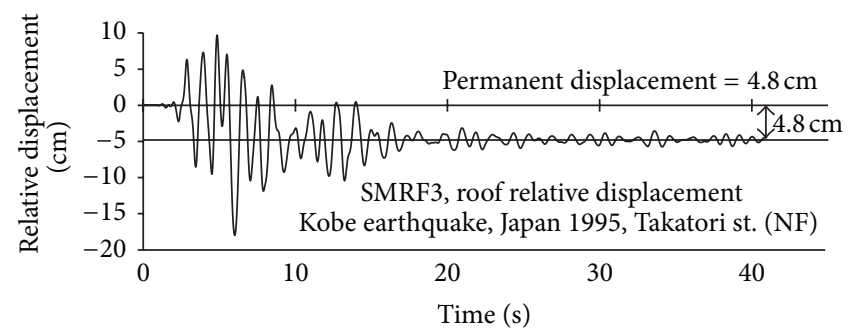

(b) Near field of fault

FIGURE 7: Displacement time history of the roof level of the 3-story model with respect to the ground in the near and far fields of the fault.

$\left(E_{\text {es }}\right)$ and inelastic $\left(E_{h}\right)$ strain energies for a multi-degree-offreedom system, respectively:

$$
\begin{gathered}
E_{k}=\int_{0}^{t} \dot{\mathbf{u}}^{T} \mathbf{M} \ddot{\mathbf{u}} d \mathbf{t}=\frac{1}{2} \dot{\mathbf{u}}^{T} \mathbf{M} \dot{\mathbf{u}}, \\
E_{\zeta}=\int_{0}^{t} \dot{\mathbf{u}}^{T} \mathbf{C} \dot{\mathbf{u}} d \mathbf{t}, \\
E_{\mathrm{es}}+E_{h}=\int_{0}^{t} \dot{\mathbf{u}}^{T} \mathbf{K u} d \mathbf{t}=\frac{1}{2} \mathbf{u}^{T} \mathbf{K u},
\end{gathered}
$$

where $\mathbf{M}$ is the mass matrix, $\mathbf{C}$ is the damping matrix, $\mathbf{K}$ is the stiffness matrix, $\mathbf{u}$ is the (relative) displacement vector of the degrees of freedom, $\mathbf{r}$ is the influence vector (the matrix of influence coefficients), $\ddot{\mathbf{u}}_{g}$ is the ground acceleration, and $t$ is the earthquake accelerograms duration [5]. The strain energy consists of elastic strain energy and inelastic (hysteresis) energy which are both included in (5). The elastic strain energy is a part of the earthquake energy which is saved in the form of elastic strain in the structural elements (which is converted into the damping and kinetic energy in the free vibration of the structure) $[4,5]$. The hysteresis energy consists of the dissipated energy by the inelastic deformations of the structural elements. After the end of the structural vibration, the percentages of the dissipated energy by damping and inelastic deformations are compared in Figure 8 for the near and far fields of the fault.

As it can be seen in Figure 8(a), by increasing the structure height, the percentage of the energy dissipated by damping in the far field of fault increases, while in the near field of fault, by increasing the structure height, the percentage of the energy dissipated by damping decreases with a mild slope. It can be seen in Figure 8(b) that by increasing the structure height, the energy dissipated by nonlinear strains in the far field of fault decreases, while in the near field of fault, by increasing the structure height, the percentage of hysteresis energy (the energy dissipated by inelastic deformations) increases with a mild slope. The averages of results of Table 2 show that in the far field of fault, damping has a more effective role in dissipating the earthquake energy specially for high rise models $(T>1 \mathrm{~s})$, in such a way that damping has dissipated about 70-95\% of earthquake input energy while the inelastic behavior of the structure has dissipated about 5-25\% of the earthquake energy. It is also seen that in the near field of fault, the high percentage of damping contribution in the energy dissipation has decreased and the energy dissipated by inelastic deformations (hysteresis energy) has increased, in such a way that in the near field of fault about $60-70 \%$ of earthquake energy has been dissipated by damping and $30-40 \%$ of the earthquake energy has been dissipated by inelastic strains of the structure. The reason for the fact that damping has an effective role in energy dissipation of high rise structures $(T>1 \mathrm{~s})$ in the far field of fault is that the distance between the principal period of the structure and the average period of the earthquake response spectrum ( $T_{m}$ in Table 1$)$ has increased, while in the near field of the fault it has decreased; thus the structure goes under the stimulation of earthquake more. The results of this section show that in both of the earthquakes of near and far fields of the fault, the maximum damping capacity of the structure is almost used, but because the oscillation energy 


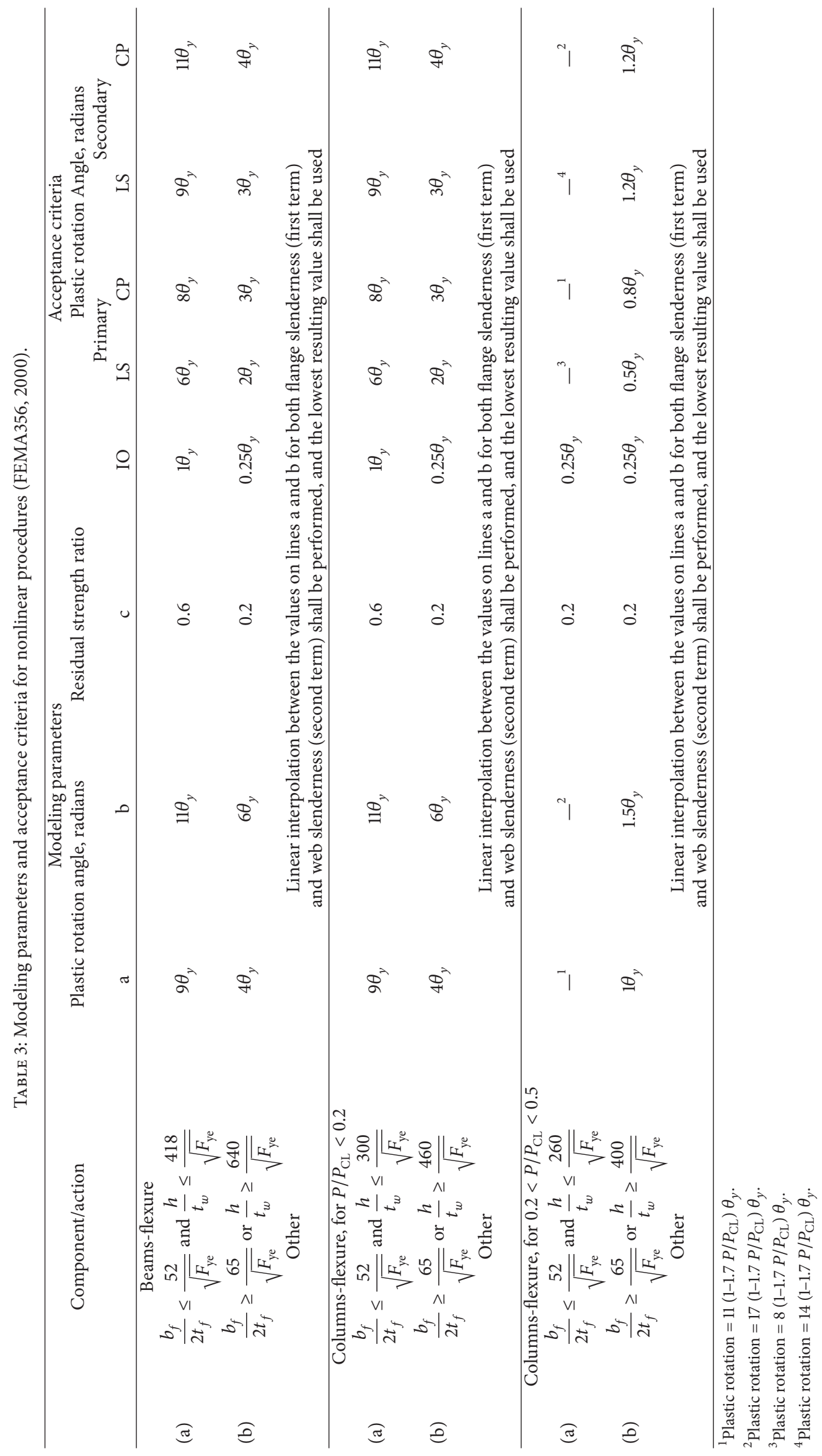




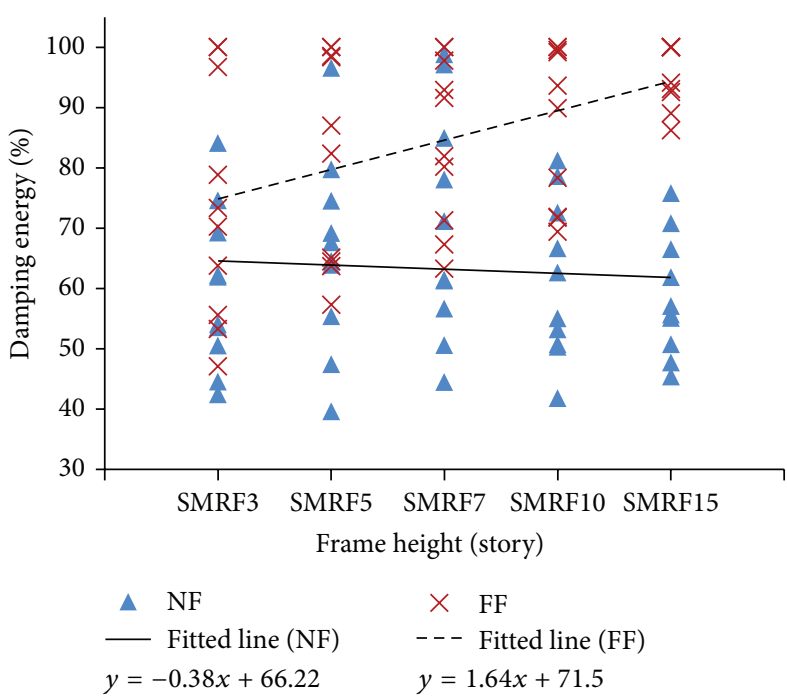

(a) Damping energy

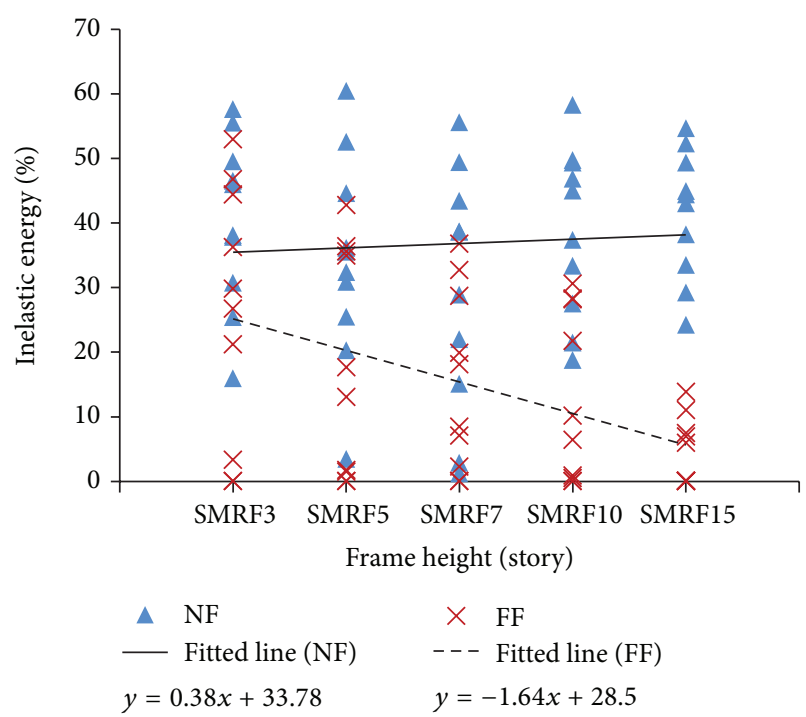

(b) Inelastic strain energy (Hysteresis Energy)

FIGURE 8: The percentage of earthquake energy dissipated by damping and inelastic deformations in the near and far fields of the fault.

in the near field of the fault is significantly higher (averagely about 2.5 times) than that in the far field of the fault, the rest of the earthquake energy is dissipated by the hysteresis energy.

\section{Investigation of Damage Distribution over the Height of the Structure}

According to previous investigations, the hysteresis energy of the structure is in relationship with the damage in the structure [5]. The amounts of input and dissipated energies in the structure represent the general performance of the structure, an indicator of the level of damage, and the amount of the structure ductility against the earthquake; but they do not indicate the way the structure behaves, the way the structure yields and collapses, and the amount of damage in different elements [4]. In mild earthquakes in which the structural behavior is elastic, the viscous damping has the main role in dissipating the earthquake energy; but in more severe earthquakes in which the structure goes under inelastic deformations, the structure energy is dissipated by viscous damping and inelastic behavior of the structural elements. Therefore, there is a direct relationship between the hysteresis energy and damage in the structure [4]. In this study, in order to investigate the earthquake damage distribution in the height of the structure in the near and far fields of the fault, the inelastic energy (the energy dissipated by hysteresis behavior) is studied for the stories of steel moment frames in the near and far fields of fault. In addition to that, in order to determine the amount of damage in the structural elements, the average of maximum ratio of demand to capacity of the structural elements of the stories in the life safety level has been used. Figure 9 shows an example of hysteresis behavior of 5-story and 15-story models for the low, middle, and top stories of the structure in the near and far fields of the fault.
According to Figure 9, in the lower stories of the structure, one or two large deformations can be seen in the hysteresis behavior of the models in the near field of fault in relation to deformations in the far field of fault which can be attributed to the effects of forward directivity. In the upper stories, this large deformation (thickening in the hysteresis curve) decreases in a way that it disappears in the uppermost story. In Figure 10, in order to investigate the inelastic energy distribution in the height of structural models, the average of percentage of dissipated energy by the inelastic deformations for each story has been given for the near and far fields of the fault.

According to Figure 10, it can be seen that the percentage of inelastic energy distribution of the stories in the height of the structure from the total hysteresis energy for the near and far fields of fault is very close (with less than $10 \%$ difference). It can also be seen that as the height increases, the maximum contribution of the hysteresis energy distribution occurs in the upper stories. Figure 10 shows that the most of the hysteresis energy (about 70-90\%) has occurred in the lower stories of the models (about $30-50 \%$ of the structure height). In order to investigate the level of the structure damages with respect to height, the average of the results of demand to capacity ratio (DCR) of the structural elements has been calculated based on FEMA356 provisions for life safety performance level. The appendix provides details of calculations for obtaining DCRs. Averages of DCRs in near and far field of fault are shown in Figure 11. The results of Figure 11 show that the demand to capacity ratio of structural elements in the near field of the fault under the pulse-like long-period ( $T_{\text {pulse }}>0.7 \mathrm{~s}$ ) motions is about 1.6 to 3 times of the corresponding value in the far field of fault in the lower part of the models, depending on the height of the structure.

The results of Figure 10 show that vulnerability is higher for the lower stories of the models. Also Figure 11 shows 

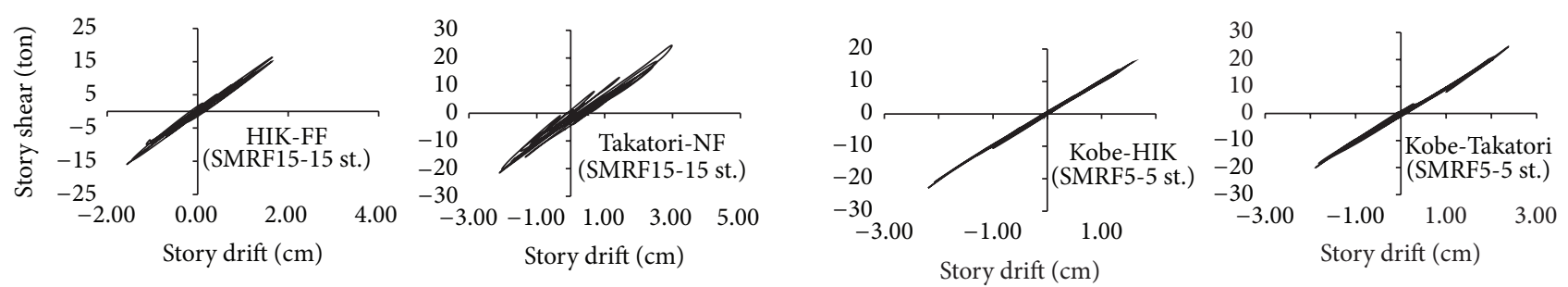

(a)
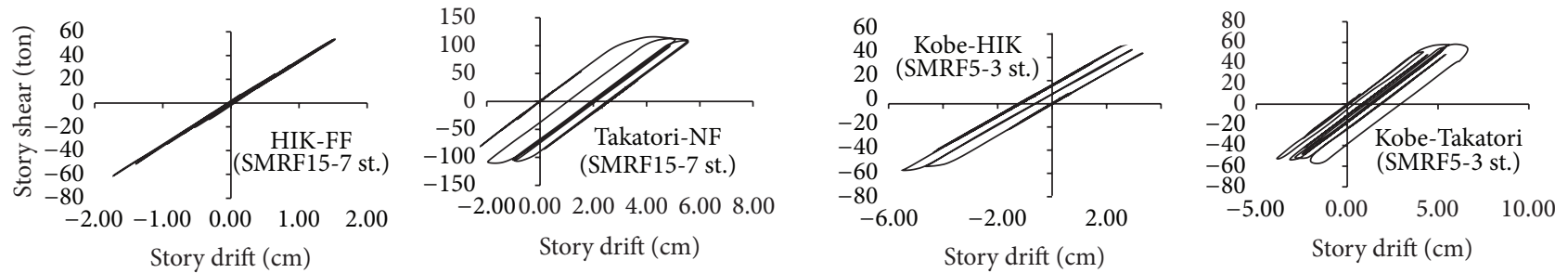

(b)
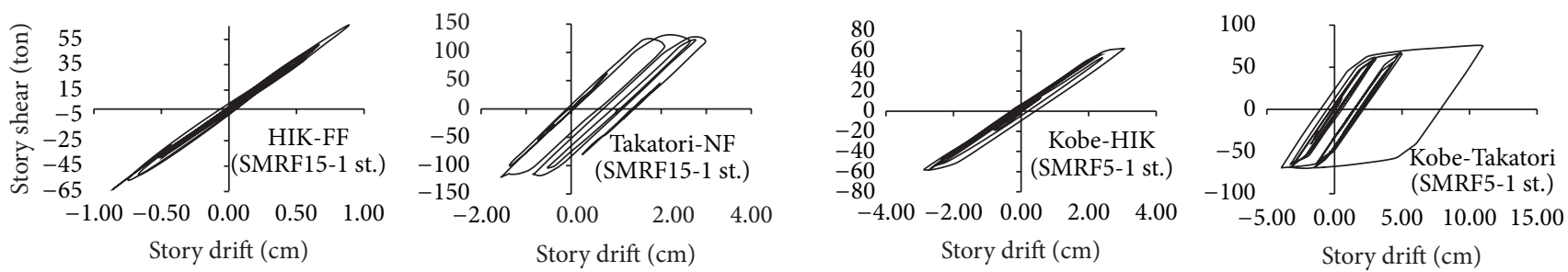

(c)

Figure 9: The hysteresis curve of low, middle, and top stories of the 5-story and 15-story models related to the Kobe, Japan, earthquake (1995) in the near and far fields of the fault (the HIK site, $R=95.72 \mathrm{~km}$, is in the far field of the fault, and Takatori site, $R=1.47 \mathrm{~km}$, is in the near field of the fault).
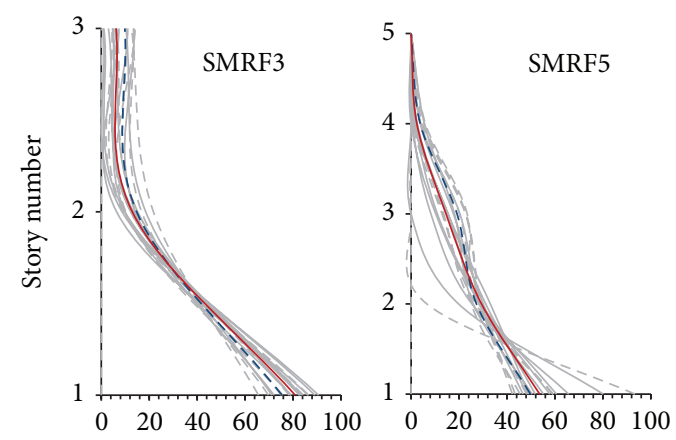

$\frac{\text { Story hysteresis energy }}{\text { Total hystresis energy }} \times 100 \frac{\text { Story hysteresis energy }}{\text { Total hystresis energy }} \times 100$
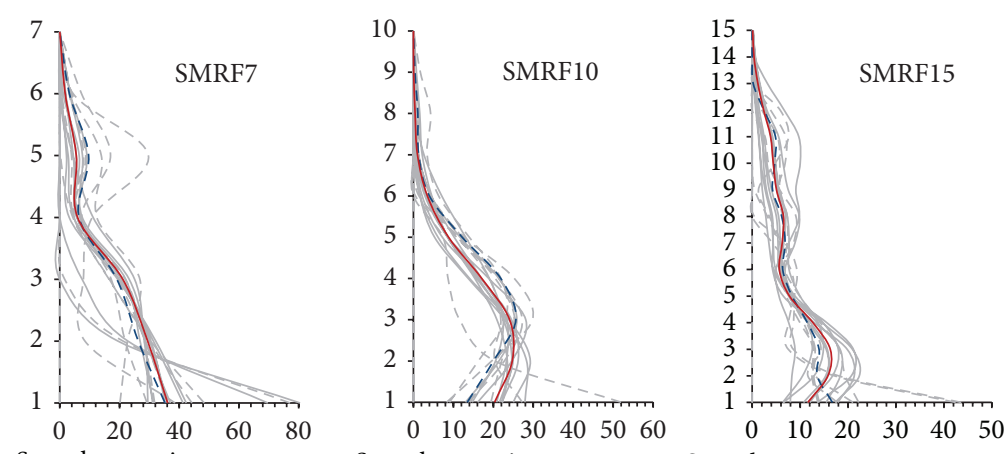

$\begin{array}{ll}-- \text { Far fault } & --- \text { Far fault } \\ - \text { Near fault } & - \text { Near fault }\end{array}$

$\frac{\text { Story hysteresis energy }}{\text { Total hystresis energy }} \times$

$\frac{\text { Story hysteresis energy }}{\text { Total hystresis energy }} \times 100$

Story hysteresis energy $\times 100$

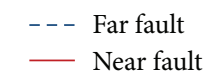

$\begin{array}{ll}\text { - } & \text { Far fault } \\ \text { — Near fault }\end{array}$

$\begin{array}{ll}-- & \text { Far fault } \\ \text { — Near fault }\end{array}$

FIGURE 10: The average of dissipated energy by inelastic deformation of the stories in the near and far fields of the fault.

that amounts of vulnerability are not equal for the near and far fields of the fault. Although the percentage of hysteresis energy distribution in the height of the structure is similar for the records of the near and far fields of fault, but the value of demand to capacity ratio of the structural elements (vulnerability) in the structure height is not the same for the near and far fields of the fault. This can be attributed by two reasons. First, as it can be seen in Figure 4, the input energy of near-fault ground motion is more than that in the far-fault ground motions which leads to increase in the hysteresis energy of the structure, in such a way that increases in the input energy and earthquake energy accumulation in 1-3 pulse-like vibration causes the earthquake input energy become larger than capacity of structure for damping energy 

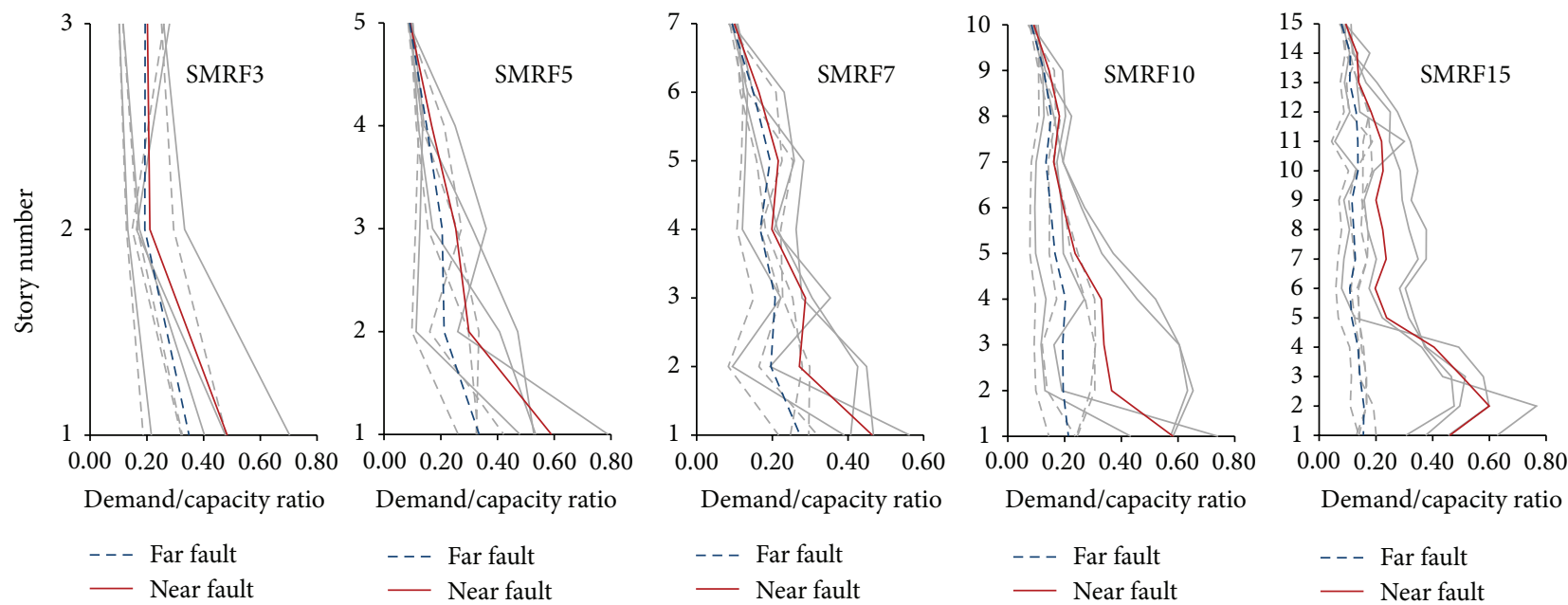

FIGURE 11: The average of the results of demand to capacity ratio (DCR) of the structural elements in the near and far fields of fault for life safety level.

dissipation during the duration of pulse vibration. Therefore the rest of energy is dissipated by the structure inelastic deformations. The second reason for the fact that the demand to capacity ratio of the structural elements is higher in the near field of the fault is the higher deformation of the structure in one direction, in such a way that if the structure deforms by a constant force in a direction, the dissipated energy will be equivalent to the situation in which the structure goes under a reciprocating deformation with the same constant force but with half of the amplitude of the first case. Therefore, since the damage level of the structural elements depends on the level of deformation (although the dissipated energy in the structural elements is constant), in a one-way displacement, they go under more deformation and are damaged more. Therefore, the type and amount of damage of the structural elements (especially at the far field of fault) cannot be determined based on the dissipated (hysteresis) energy of the story. Anyway, the distribution of the damage in the structure can be determined based on the dissipated (hysteresis) energy of the story. In the near fields of the fault, the forward directivity effect of the pulse-like long period motion of the ground ( $T_{\text {pulse }}>0.7 \mathrm{~s}$ ) causes the structure to go under a very large deformation in one direction in a short time and under 1-3 pulses with high amplitude and long oscillation period as most of the input energy (about $70-90 \%$ of it) is dissipated in the $30-50 \%$ lower part of the structure which then leads to increase in the ductility demand and demand to capacity ratio of the structure elements in the $30-50 \%$ of lower stories of the structure.

\section{Conclusions}

In this study, in order to investigate the pattern of vulnerability distribution and the level of damage in the steel moment frames under the effect of far and near fault ground motions, 5 steel moment frame models with $3,5,7,10$, and 15 stories under 20 earthquake records were investigated with the help of the structure energy equilibrium equation, and the following conclusions were drawn.

(1) The increase rate (or slope) of the earthquake input energy with respect to increase in the number of stories of the structure for the near field of the fault is triple of that of the far field of the fault, in such a way that the average ratio of input energy of near field of fault over the far field of the fault is 1.27 for the 3story model, while it has reached 2.5 for the 15 -story model. Therefore pulse-like vibrations of the ground in the near field of fault have more destructive effects on the high rise long period structures $(T>0.7 \mathrm{~s})$ in comparison with low rise structures.

(2) In the far field of fault, damping has dissipated about $70-95 \%$ of earthquake input energy while the inelastic behavior of the structure has dissipated about $5-25 \%$ of the earthquake energy, while in the near field of fault about $60-70 \%$ of earthquake energy has been dissipated by damping and $30-40 \%$ of the earthquake energy has been dissipated by inelastic strains of the structure. Therefore damping has an effective role in energy dissipation of high rise structures $(T>1 \mathrm{~s})$ in the far field of fault, while in the near field of the fault the contribution percentage of damping has decreased; thus the value of energy dissipation by the inelastic deformations (hysteresis energy) increases. It must be stated that in both of the earthquakes of near and far fields of the fault, the maximum damping capacity of the structure is almost used, but because the oscillation energy in the near field of the fault is significantly higher (about 1.3-2.5 times) than that in the far field of the fault, the rest of the earthquake energy is dissipated by the hysteresis energy.

(3) Investigation of the inelastic (hysteresis) energy distribution shows that the most of the hysteresis energy (about 70-90\%) has occurred in the lower stories of the models (about $30-50 \%$ of the structure height 
at low). Even though the shape of hysteresis energy distribution at the structure height is similar for the near and far fields of the structure, but because of higher energy of the near-fault ground motions (about 2.5 times) and the low number of reciprocating oscillations of the ground pulse-like vibrations in the near field of the fault, the forward directivity effect increases the demand to capacity ratio of the structural elements in the $30-50 \%$ lower stories of the structure, significantly. Therefore by assuming the same PGA for the near and far fields of the fault, the demand to capacity ratio of structural elements in the near field of the fault under the pulse-like longperiod $\left(T_{\text {pulse }}>0.7 \mathrm{~s}\right)$ in the lower part of the models, depending on the height of the structure, is about 1.6 to 3 times of the corresponding value in the far field of fault.

\section{Appendix}

\section{Modeling Criteria in This Study}

See Figure 2 and Table 3.

In the appendix, nonlinear modeling and process to identification of demand to capacity ratio (DCR) of structural elements are explained based on FEMA356.

FEMA356 has divided structural elements to three groups of brittle (nonductile), semiductile, and ductile elements. Nonductile elements are force-control and ductile elements are deformation-control. DCR of force-control elements is identified by

$$
\mathrm{DCR}=\frac{\mathrm{Q}_{\mathrm{UF}}}{\kappa \mathrm{Q}_{\mathrm{CL}}} .
$$

Axial behavior of columns is force-control, but flexural behavior of steel columns depends on the level of axial compression force of columns. For steel columns, which are under combined axial compression and bending stress, when axial compression force is less than $50 \%$ of axial lower-bound of column capacity $\left(P_{\mathrm{CL}}\right)$, the column flexural behavior is deformation-control. If the axial force is more than $50 \%$ of axial lower-bound of column capacity $\left(P_{\mathrm{CL}}\right)$, the flexural behavior of column is force-control. Equation (A.2) is used to identify DCR of force-control columns under combination of compression axial and flexural forces:

$$
\mathrm{DCR}=\frac{P_{\mathrm{UF}}}{P_{\mathrm{CL}}}+\frac{M u_{F x}}{M_{\mathrm{CL} x}}+\frac{M u_{F y}}{M_{\mathrm{CL} y}} \leq 1 .
$$

Steel columns under axial tension and moment forces are considered as deformation-control elements.

For deformation-control elements, based on FEMA356, the ratio of maximum rotation of elements to allowable rotation is considered by

$$
\mathrm{DCR}=\frac{\theta_{\text {Max }}}{\theta_{\text {Allowable }}} .
$$

According to (A.3), $\theta_{\max }$ is the maximum rotation of structural element obtained by nonlinear dynamic analysis and $\theta_{\text {allowable }}$ is the maximum rotation capacity of structural element obtained from Table 3 based on FEMA356. $\theta_{\text {allowable }}$ is defined by coefficient of $\theta_{y} . \theta_{y}$ is the maximum elastic rotation of elements calculated by (A.4) and (A.5) for girders and columns respectively.

Maximum elastic rotation capacity of girders is as follows:

$$
\theta_{y}=\frac{Z F_{\mathrm{ye}} l_{b}}{6 E l_{b}}
$$

Maximum elastic rotation capacity of columns is as follows:

$$
\theta_{y}=\frac{Z F_{\mathrm{ye}} l_{c}}{6 E l_{c}}\left(1-\frac{P}{P_{\mathrm{ye}}}\right) \text {. }
$$

Maximum plastic moment strength of girders is as follows:

$$
Q_{\mathrm{CE}}=M_{\mathrm{CE}}=Z F_{\mathrm{ye}} \text {. }
$$

Maximum plastic moment strength of columns is as follows:

$$
\mathrm{Q}_{\mathrm{CE}}=M_{\mathrm{CE}}=1.18 Z F_{\mathrm{ye}}\left(1-\frac{P}{P_{\mathrm{ye}}}\right) \leq Z F_{\mathrm{ye}} \text {. }
$$

Also, to nonlinear modeling of moment frames, plastic hinge of elements, force-deformation curves is obtained by (A.4) to (A.7), Figure 2 and Table 3 based on FEMA356.

Parameters used in the appendix are defined by FEMA356 and listed as follows.

$\theta_{y}$ : Yield rotation of structural element

$E$ : Module of elasticity

$F_{\text {ye }}$ : Expected yield strength of the material

$I_{b}$ : Moment of inertia for beam section

$I_{c}$ : Moment of inertia for column section

$\kappa$ : Knowledge factor defined in FEMA356, Section 2.2.6.4

$l_{b}$ : Beam length

$l_{c}$ : Column length

$M_{\mathrm{CE}}$ : Expected bending strength

$M_{\mathrm{CL} x}$ : Lower-bound flexural strength of the member about the $x$-axis

$M_{\mathrm{CL} y}$ : Lower-bound flexural strength of the member about the $y$-axis

$M_{\mathrm{UF} x}$ : Bending moment in the member about the $x$ axis, Section 3.4.2.1.2 of FEMA356

$M_{\mathrm{UF} y}$ : Bending moment in the member about the $y$ axis, Section 3.4.2.1.2 of FEMA356

$P$ : Axial force in the member at the instant of computation for nonlinear dynamic analyses

$P_{\mathrm{CL}}$ : Lower-bound compression strength of the column 
$P_{\mathrm{UF}}$ : Axial force in the member computed in accordance with Section 3.4.2.1.2 of FEMA356

Q: Generalized component load

$Q_{\mathrm{CE}}$ : Generalized component expected strength

$Q_{\mathrm{CL}}$ : Lower-bound strength of a component or element

$Q_{\mathrm{UF}}$ : Force-controlled design action due to gravity loads in combination with earthquake loads

$Q_{y}$ : Yield strength of the component

$Z$ : Plastic section module.

\section{Conflict of Interests}

The authors of this paper confirm that there is no conflict of interests in this paper.

\section{References}

[1] F. Haddad-Shargh and M. Hosseini, "An optimal distribution of stiffness over the height of shear buildings to minimize the seismic input energy," Journal of Seismology and Earthquake Engineering, vol. 13, no. 1, pp. 25-32, 2011.

[2] S. M. Zahrai, S. Dastmalchi, and S. R. Mirghaderi, "Extending seismic design of steel moment frames using energy-based method," Journal of Sazeh va Folad (Structure and Steel), vol. 5, no. 6, pp. 89-92, 2009 (Persian).

[3] G. W. Housner, "Limit design of structures to resist earthquakes," in Proceedings of 1st World Conference on Earthquake Engineering, vol. 5, pp. 1-13, Earthquake Engineering Research Institute, Oakland, Calif, USA, 1956.

[4] G. Abdollahzadeh and A. Alehashem, "Energy distribution in stories of concentrically braced frames (CBFs) under far-field and near-field records," Journal of Sazeh va Folad (Structure and Steel), vol. 6, no. 7, pp. 31-41, 2010 (Persian).

[5] P. Khashaee, B. Mohraz, F. Sadek, H. S. Lew, and J. L. Gross, "Distribution of earthquake input energy in structures," Tech. Rep. NISTIR 6905, United States Department of Commerce Technology Administration, National Institute of Standards and Technology, Gaithersburg, Md, USA, 2003.

[6] S. Leelataviwat, S. C. Goel, and B. Stojadinović, "Toward performance-based seismic design of structures," Earthquake Spectra, vol. 15, no. 3, pp. 435-461, 1999.

[7] J. P. Stewart, C. S. Chiou, J. D. Bray, R. W. Graves, P. G. Somerville, and N. A. Abrahamson, "Ground motion evaluation procedures for performance-based design," Research Report Conducted Under Grant EEC-9701568, National Science Foundation, University of California, Berkeley, Calif, USA, 2001.

[8] B. A. Bolt, "Seismic input motions for nonlinear structural analysis," Journal of Earthquake Technology, vol. 448, pp. 223232, 2004.

[9] B. Alavi and H. Krawinkler, "Behavior of moment-resisting frame structures subjected to near-fault ground motions," Earthquake Engineering and Structural Dynamics, vol. 33, no. 6, pp. 687-706, 2004.

[10] F. Soleimani Amiri, G. Ghodrati Amiri, and H. Razeghi, "Estimation of seismic demands of steel frames subjected to nearfault earthquakes having forward directivity and comparing with pushover analysis results," Structural Design of Tall and Special Buildings, vol. 22, no. 13, pp. 975-988, 2012.
[11] M. Tehranizadeh and P. Boroumand, "Performance-based design of seismically isolated steel structures with ordinary occupancy," Journal of Sharif Civil Engineering, vol. 27-2, no. 1, pp. 87-94, 2011 (Persian).

[12] H. Jahan Khah, M. Behzad, and M. A. Ghanad, "Internal strain energy of structures in the near field earthquakes," Journal of Sharif Civil Engineering, vol. 24, pp. 35-39, 2009 (Persian).

[13] M. Tehranizadeh and H. Taheri, "Effective parameters on design spectra in near-fault and proposed spectrum using forward directivity," Journal of Sharif Civil Engineering, vol. 27-2, no. 1, pp. 107-113, 2011 (Persian).

[14] J. W. Baker, "Quantitative classification of near-fault ground motions using wavelet analysis," Bulletin of the Seismological Society of America, vol. 97, no. 5, pp. 1486-1501, 2007.

[15] M. Gerami and D. Abdollahzadeh, "Estimation of forward directivity effect on design spectra in near field of fault," Journal of Basic and Applied Scientific Research, vol. 2, no. 9, pp. 86708686, 2012.

[16] M. Gerami and D. Abdollahzadeh, "Local and global effect of forward directivity," Journal of Croatian Association of Civil Engineers, Hrcak, vol. 65, no. 11, 2013.

[17] S. R. Hoseini Vaez, M. K. Sharbatdar, G. R. Ghodrati-Amiri, H. Naderpour, and A. Kheyroddin, "Dominant pulse simulation of near fault ground motions," Earthquake Engineering and Engineering Vibration, vol. 12, no. 2, pp. 267-278, 2013.

[18] Standard No. 2800, Iranian Code of Practice for Seismic Resistant Design of Buildings, Ministry of Housing and Urban Development of Iran, Tehran, Iran, 3rd edition, 2005.

[19] FEMA 356, Prestandard and Commentary For the Seismic Rehabilitation of Buildings, Federal Emergency Management Agency (FEMA), Washington, DC, USA, 2000. 

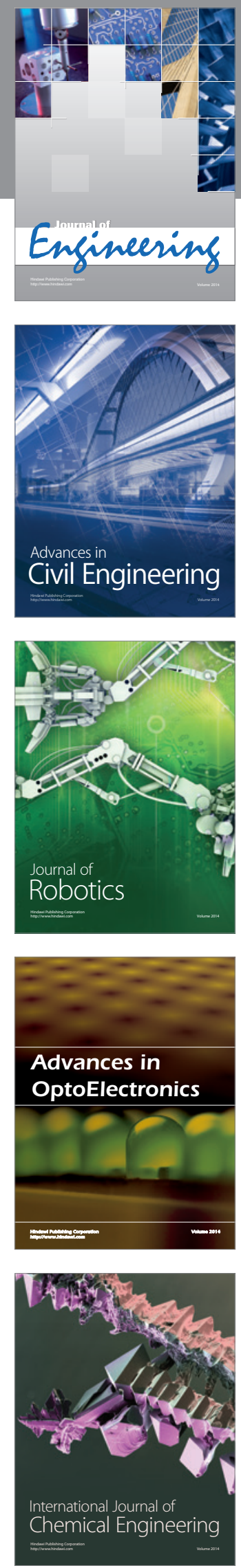

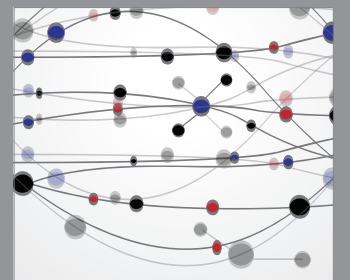

The Scientific World Journal
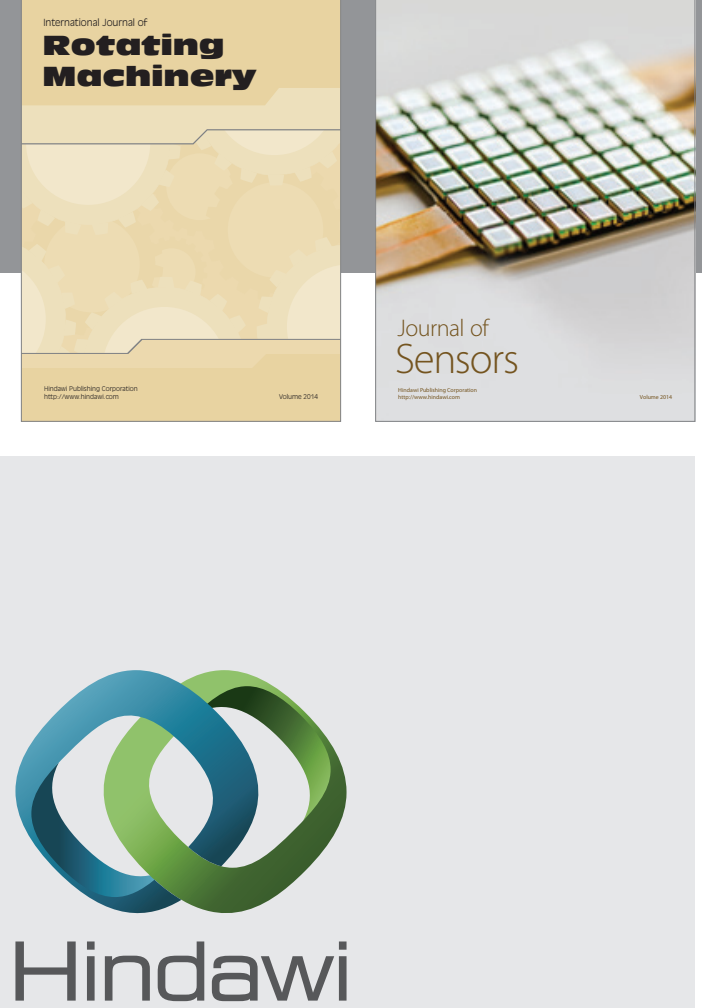

Submit your manuscripts at http://www.hindawi.com
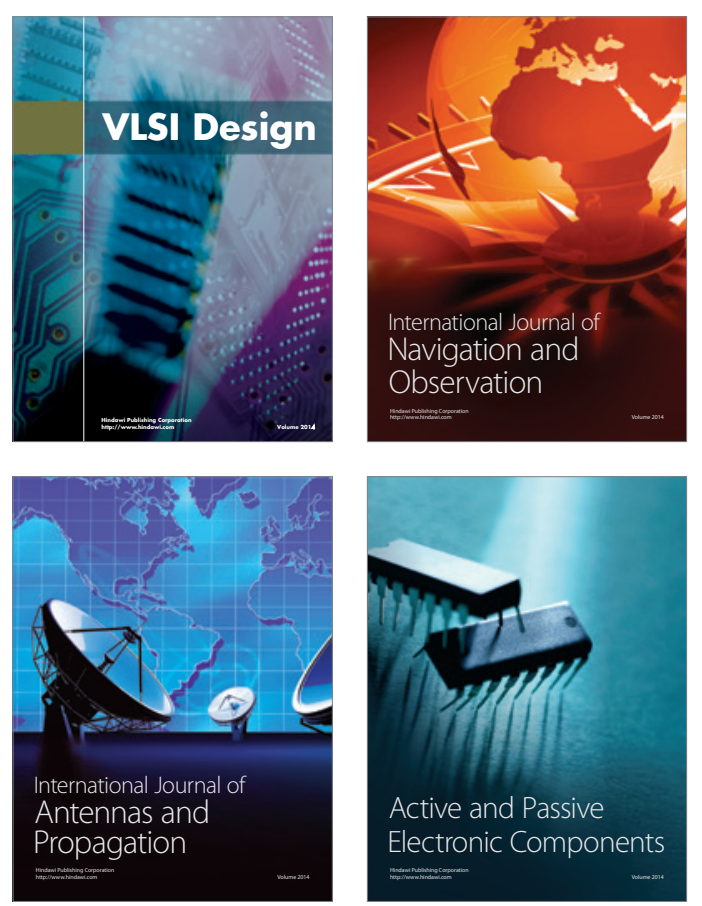
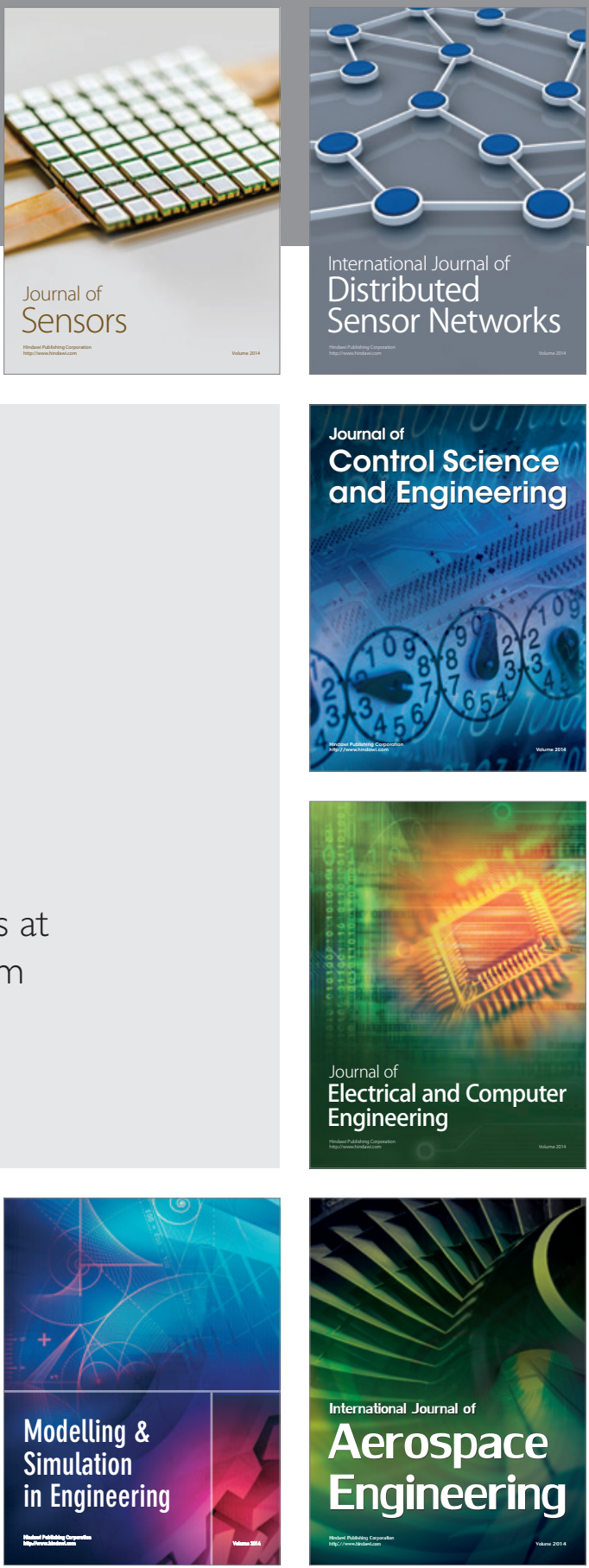

Journal of

Control Science

and Engineering
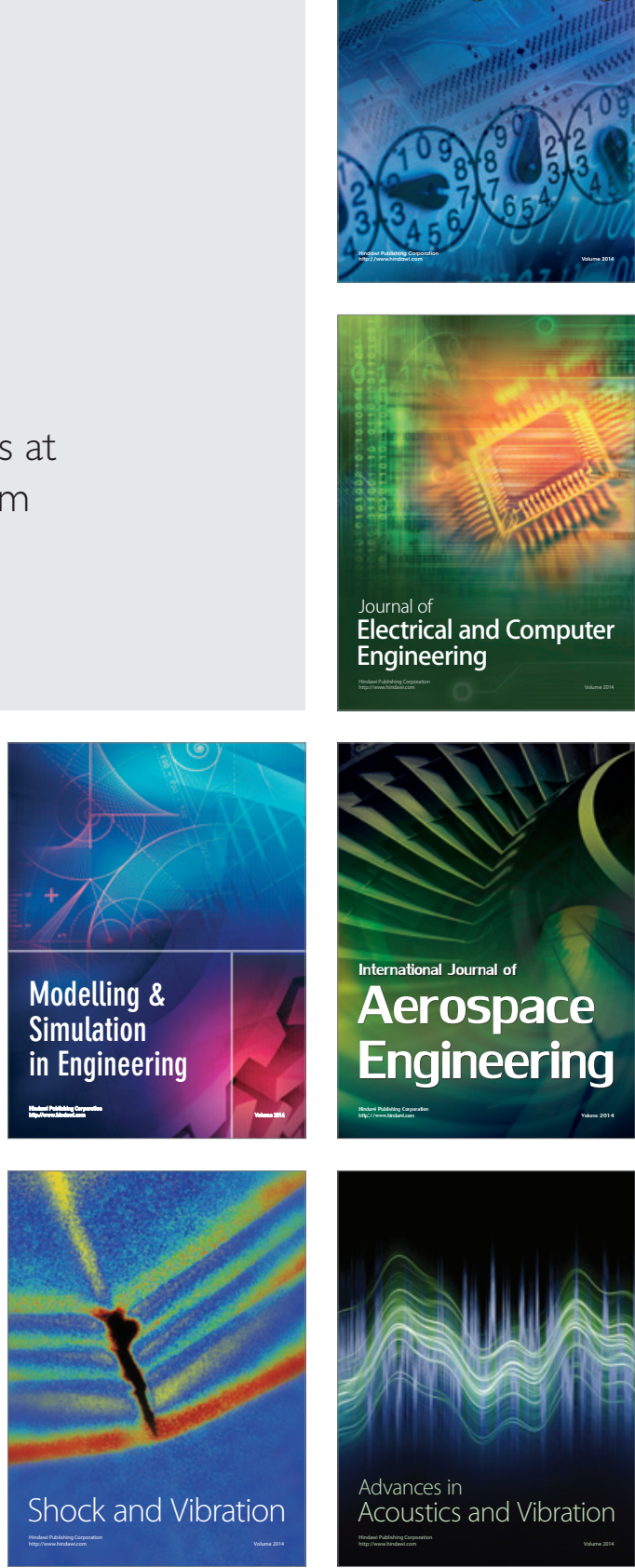